\title{
Role of premorbid status and wound related factors in surgical site infection in a tertiary hospital in sub-saharan Africa
}

Joy Oluchi Osakwe', Godswill Amechi Nnaji ${ }^{1 *}$, Richmond Chukwudi Osakwe ${ }^{2}$, Uloma Agu ${ }^{1}$ and Henry Nnaemeka Chineke ${ }^{3}$

*Correspondence: godswilln@yahoo.co.uk

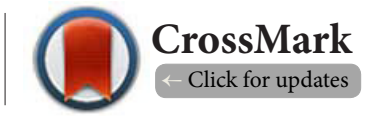

'Department of Family Medicine, Nnamdi Azikiwe University Teaching Hospital, Nnewi, Nigeria.

2Department of Obstetrics and Gynaecology, Nnamdi Azikiwe University Teaching Hospital, Nnewi, Nigeria.

${ }^{3}$ Department of Family Medicine, Imo State University Teaching Hospital, Orlu, Imo State, Nigeria.

\begin{abstract}
Background: Surgical site infection (SSI) is the commonest hospital acquired infection in surgical patients globally. It has remained a major cause of morbidity and mortality and a major source of worry to both the patients, doctors, hospitals and the community as a whole.

$\underline{\text { Aim: }}$ To determine the role of premorbid status, wound class and cadre of surgeons on the prevalence rate of surgical site infections.

Materials and methods: This was a cross-sectional study involving 200 randomly recruited surgical patients between April and June 2012 at Nnamdi Azikiwe University Teaching Hospital, Nnewi. Pre-tested, interviewer administered questionnaires and laboratory test results were used to collect data, which were analyzed using Statistical Package for Social Sciences, version 16.
\end{abstract}

Results: The prevalence of surgical site infection was $15.5 \%$ (or 31 of 200) among the participants. Premorbid status, as well as, wound class, of the patients affected the rate of SSI $(p=0.007)$ and $(p=0.009)$, respectively. However, the wound location did not show any significant effect on the prevalence of SSI.

Conclusion: The study found a high prevalence of SSI which was dependent on the class of wound, and premorbid status of the patient.

Keywords: Surgical site infection, wound class, nosocomial infection, premorbid status

\section{Introduction}

\section{Background}

Surgical site infection (SSI) is the commonest hospital acquired infection in surgical patients globally $[1,2]$. SSI was previously referred to as surgical wound infection but recently it's been defined as infection occurring within 30 days after a surgical operation (or within one year if an implant is left in place after the procedure) and affecting either the incision or deep tissue at the operation site $[2,3]$. The infection could either be superficial or deep, incisional, or involving organs or body spaces.

In United States of America, SSI annual incidence is between $2.0 \%$ and $5.0 \%$ despite the improvement in surgical technique, advances in infection control practices, and a near universal practice of peri-operative antibiotic prophylaxis [4].

SSI rate in Japan is $15.0 \%$ of all nosocomial infections [5]. According to WHO, the risk of SSI in developing countries is higher than in equivalent surgical procedures carried out in high-income countries. This is especially so in sub-Saharan Africa [6,7].

SSI rate in Tanzania is $26 \%$, while the incidence for Uganda is $58.5 \%[8,9]$.

$\mathrm{SSI}$ rate in children undergoing surgery operation in Zaria is $23.6 \%$ [10]. Ameh et al., reported SSI rate of $14.3 \%$ in clean incisions, $19.3 \%$ in clean-contaminated incisions, $27.3 \%$ in contaminated incisions, and $60 \%$ in dirty incisions. Emergency procedure has a higher rate $(25.8 \%)$ than elective procedure (20.8\%). Poor nursing services and poor hospital hygiene have also been implicated as risk factors in the study [10].

Osifor et al., found SSI rate of $11.8 \%$ in neonatal surgical operation in Benin City [11]. Ojiyi et al., working in a tertiary hospital, in southeastern Nigeria found SSI rate of $11.0 \%$ among patients who had caesarean section [12]. 
The effect of SSI on the patient include discomfort, delay in wound healing, wound dehiscence, gas gangrene and tetanus. Consequently, SSI could lead to prolonged hospitalization, increased economic burden to the patient/family and may impose substantial demand on healthcare resources.

Without medical insurance, dependence on cash payment at point of service by patients may lead to untold hardship to the families of the sick. Hence many families risk selling off or mortgaging family lands in order to settle hospital bills.

It is therefore, important to elucidate some of the factors associated with SSI in our hospitals. This will contribute to the literature and knowledge necessary for a change in the approach to a better surgical management.

Risk factors for SSI may be grouped under the following headings; patient factors, surgeon's factor, environmental factors and non-surveillance in health facilities.

\section{General objective}

To determine the association between premorbid status and wound related risk factors on the prevalence rate of surgical site infections in NAUTH, Nnewi.

\section{Specific objectives}

Specifically, to determine the effect of premorbid status on $\mathrm{SSl}$; and to identify wound related risk factors associated with SSI in the study population.

\section{Methods}

\section{Study location}

The study location was Nnamdi Azikiwe University Teaching Hospital, (NAUTH), Nnewi, a tertiary Federal Government owned health institution with various surgical sub-specialties. The hospital has well equipped main theatre with four surgical operating suites, and a dedicated theatre for obstetrics and gynaecologic emergencies. Approximately, 45 surgical procedures were performed weekly or a total of 1,726 in 2012.

\section{Study design}

This was a cross sectional study involving patients who were operated upon at NAUTH, Nnewi between April and June 2012.

\section{Study population}

The study population was adults aged 18 years and above, who were operated at NAUTH and who were admitted in the surgical wards.

\section{Inclusion criteria}

All surgical patients aged 18 years and above whose surgical operation were done at NAUTH, Nnewi within the study period.

\section{Exclusion criteria}

Critically ill patients including patients with full blown AIDS and those involved in road traffic accidents. Patients whose surgical operation were not done at NAUTH, Nnewi were excluded from the study.

\section{Sample size determination}

This was calculated from the formula $\mathrm{N}=\mathrm{Z}^{2} \mathrm{pq} / \mathrm{d}^{2}$ [13]. Where $\mathrm{N}=$ Desired sample size; $\mathrm{Z}=$ Standard normal deviation (1.96. or $95 \%$ confidence interval); $\mathrm{P}=$ Incidence of $\mathrm{SSI}$ in Anambra state by Ojiyi et al $=11 \%$ [12].

$\mathrm{Q}=1-\mathrm{P} ;$ and $\mathrm{d}=$ Degree of accuracy/precision expected $=0.05$. The sample size was increased to 200 [14].

\section{Sample/data collection}

The surgical wards were visited daily for collection of wound swab for the 3 months duration of the study. The nursing staffs of the surgical wards assisted by keeping the researchers informed of the time that the wound dressing would be opened for inspection and changing of wound dressing. Care was exercised in order not to contaminate the wound.

\section{Sampling technique}

The researchers obtained daily list of eligible patients for surgical operation to be included in the study from the theatre staff. Numbered ballot papers were assigned to each name on the list and there after, they were packed into a nylon bag. Half of the number of the eligible people were blindly picked from the nylon bag by simple random method and these selected persons were then approached to participate in the study. After thorough explanation, those that consented signed a written consent form, and were enrolled into the study. Surgical wounds were observed on the $3^{\text {rd }}$ post-operative day for infection before change of dressing. The wound was also observed on the $5^{\text {th }}$ and $7^{\text {th }}$ post-operative days before removal of alternate sutures, or whenever there was suspicion or evidence of infection, and finally at discharge.

Aseptic procedures of hand washing, use of sterile gloves and masking was observed by the researcher every time the wound was exposed. Wound swab was collected with sterile swab stick from surgical sites of each enrolled patient. The evidence of SSI include fever, redness, discharge or dehiscence. The specimens were immediately transported to the microbiology laboratory, within 10 minutes of collection. All the patients enrolled into the study were monitored for SSI until discharged from the hospital.

The study instruments include pre-tested questionnaires, weighing scale, and sterile swab sticks.

\section{Process of microscopy, culture and sensitivity}

In the microbiology laboratory, the wound swabs were cultured onto chocolate agar and MacConkey agar and incubated aerobically at $37^{\circ} \mathrm{C}$ for $18-24$ hours. It was extended to 48 hours if no bacterial growth was seen within 24 hours.

\section{Morphological measurement}

Using a validated weighing scale combined with stadiometer manufactured by Techmel and Techmel USA TT 120, the weight 
was read off to the nearest $0.1 \mathrm{~kg}$. The validity of the scale was checked every day before data collection using a known weighted object $(10 \mathrm{~kg})$. The height was taken with the stadiometer with the patients standing upright looking straight forward, with back straight, heels against the scale, without shoes, cap or scarf. The pointer of the height meter was pressed firmly against the scalp and read off on the meter scale to the nearest $0.5 \mathrm{~cm}$. The manufacturer's standing operating procedures were followed.

\section{Data collection}

Data was collected using pretested interviewer administered questionnaire on the following items; socio-demographic, pre-morbid status, surgical wound site, surgeon, pre-operative antibiotic used, outcome of wound swab culture, and outcome of the surgical operation.

\section{Definitions and diagnostic criteria Site of surgical operation}

Surgical procedures were categorized into abdominal surgical procedure, head and neck, chest, back and extremities.

\section{Type of operation}

The type of surgical operation is referred to as minor or major based on NAUTH, Nnewi surgery categorization. Minor surgical procedures include lumpectomy, lipoma excision, incision and drainage, simple herniorrhaphy and thoracotomy, while major surgical operation include caesarean section, laparotomy, hysterectomy, gastrectomy, myomectomy and complicated herniorrhaphy.

\section{Wound classification [2]}

Class1 or Clean: An uninfected operative wound in which no inflammation is encountered and no viscus is entered.

Class II or Clean-Contaminated: An operative wound in which the respiratory, alimentary, genital, or urinary tracts are entered under controlled conditions and without unusual contamination.

Class III or Contaminated: Open, fresh, accidental wounds. Surgical procedures with major breaks in sterile technique or gross spillage from the gastrointestinal tract. Class IV or DirtyInfected: Old traumatic wounds with retained devitalized tissue.

\section{Criteria for defining surgical site infections [2] Superficial incisional SSI}

Infection occurs within 30 days after the operation and infection involves only skin or subcutaneous tissue of the incision and at least one of the following:

1. Purulent drainage, from the superficial incision.

2. Organisms isolated from fluid or tissue from the superficial incision.

3. At least one of the following; pain or tenderness, swell ing, redness, or heat.

4. Diagnosis of superficial incisional SSI.

\section{Deep incisional SSI}

Infection occurs within 30 days after the operation if no implant is left in place, or within one year if implant is in place and the infection appears to be related to the operation, or involves deep soft tissues (e.g., fascia and muscle layers) of the incision and at least one of the following:

1. Purulent drainage from the deep incision but not from the organ/space component of the surgical site.

2. A deep incision spontaneously dehisces or is deliberately opened by a surgeon when the patient has at least one of the following signs or symptoms: Fever $\left(>38^{\circ} \mathrm{C}\right)$, localized pain or tenderness, unless site is culture-negative.

3. An abscess or other evidence of infection involving the deep incision is found on direct examination, during reoperation, or by histopathology or radiologic examination.

4. Diagnosis of a deep incisional SSI by a surgeon or an attending physician.

Note: Infection that involves both superficial and deep incision sites are reported as deep incisional SSI. An organ/space SSI that drains through the incision is reported as a deep incisional SSI.

\section{Organ/space SSI}

Infection occurs within 30 days after the operation if no implant is left in place or within one year if implant is in place and the infection appears to be related to the operation and infection involves any part of the anatomy (e.g., organs or spaces) other than the incision, which was opened or manipulated during an operation and at least one of the following:

1. Purulent drainage from a drain that is placed through a stab wound into the organ/space.

2. Organisms isolated from an aseptically obtained culture of fluid or tissue in the organ/space.

3. An abscess or other evidence of infection involving the organ/space that is found on direct examination, during reoperation, or by histopathology or radiologic examination.

4. Diagnosis of an organ/space SSI by a surgeon or attending physician.

Socio-Economic Classification was done along classification reported in Wikipedia [15].

\section{Data analysis}

Analysis was done using Statistical Package for the Social Sciences (SPSS) version 16. The level of statistical significance was $5 \%$.

\section{Ethical precepts}

Ethical clearance was obtained from the ethical committee of NAUTH. Confidentiality was maintained throughout the study. The patients were informed of their right to withdraw from the study any time they wished to do so without consequences. Patients included in the study were informed 
of their BMI and the results of the wound swab culture and sensitivity was voluntarily handed over to the surgical team managing the patients.

\section{Results}

The age range of the participants was 18 years to 75 years, Mean \pm STD of $34.47 \pm 11.77$ years. Highest proportion of the participants consisted of those younger than 30 years 91 $(45.5 \%)$, the least were those in the $50-59$ age group (5.0\%) (Table 1).

Females were more in proportion $(144,72 \%)$ than males $(56,28 \%)$, giving a male-female ratio of 1:2.6.

A higher percentage of the participants $(114,57.0 \%)$ had secondary education, while the least had no formal eduction $(4,2.0 \%)$.

Table 1. Distribution of socio-demographic characteristics.

\begin{tabular}{|c|c|c|}
\hline & Frequency (n) & Percentage (\%) \\
\hline \multicolumn{3}{|l|}{ Age in years } \\
\hline$<30$ & 91 & 45.5 \\
\hline $30-39$ & 67 & 33.5 \\
\hline $40-49$ & 19 & 9.5 \\
\hline $50-59$ & 10 & 5.0 \\
\hline$\geq 60$ & 13 & 6.5 \\
\hline \multicolumn{3}{|l|}{ Sex } \\
\hline Male & 56 & 28 \\
\hline Female & 144 & 72 \\
\hline \multicolumn{3}{|l|}{ Educational level } \\
\hline Tertiary & 45 & 22.5 \\
\hline Secondary & 114 & 57.0 \\
\hline Primary & 37 & 18.5 \\
\hline None & 4 & 2.0 \\
\hline \multicolumn{3}{|l|}{ Occupational status } \\
\hline Trading & 85 & 42.5 \\
\hline Student/unemployed & 42 & 21.0 \\
\hline Civil servant & 25 & 12.5 \\
\hline Technicians & 22 & 11.0 \\
\hline Others & 14 & 7.0 \\
\hline Professionals & 12 & 6.0 \\
\hline \multicolumn{3}{|l|}{ Socio-economic class } \\
\hline Higher & 23 & 11.5 \\
\hline Middle & 73 & 36.5 \\
\hline Lower & 104 & 52.0 \\
\hline \multicolumn{3}{|l|}{ Marital status } \\
\hline Married & 158 & 79.0 \\
\hline Single & 30 & 15.0 \\
\hline Widowed & 11 & 5.5 \\
\hline Separated & 1 & 0.5 \\
\hline \multicolumn{3}{|c|}{ Body mass index $\left(\mathrm{Kg} / \mathrm{m}^{2}\right)$} \\
\hline Under weight $(<18)$ & 1 & 0.5 \\
\hline Normal (18-25) & 42 & 21.0 \\
\hline Over weight (26-29) & 106 & 53.0 \\
\hline Obesity (30-35) & 37 & 18.5 \\
\hline Morbid obesity (>35) & 14 & 7.0 \\
\hline
\end{tabular}

Traders were more $(85,42.5 \%)$, while professionals constituted the least $(12,6.0 \%)$. More than half of the participants belong to the lower socioeconomic, while less than one quarter were in the higher socioeconomic class 23 (11.5).

A majority of the participants were married $(158,79.0 \%)$, while $15.0 \%$ were single. A majority of the participants were overweight, $(106,53.0 \%)$, only $21 \%$ had normal BMI.

The entire 31 swabs collected and cultured from SSI's yielded growth on culture (see Table 2) with Staphylococcus aureus being the commonest isolated organism (19 of 31, 61.3\%) and Streptococcus pyogenes $(3,9.7 \%)$ the least.

Approximately, half of the participants had the clean wound $(103,51.5 \%)$, while dirty wound was the least $(9,4.5 \%)$. Abdominal surgery was the commonest $(182,91.0 \%)$ (see Table 3 ). Others surgeries, involving the back, chest and extremities madeup 18, 9.0. A majority of the surgical procedure was classified as major $(179,89.5 \%)$.

Most of the surgeries were performed by the senior registrars $(144,72.0 \%)$, while consultants did $53,26.5 \%$ of the surgeries.

Table 2. Distribution of preoperative antibiotics and culture yield.

\begin{tabular}{lll}
\hline & $\begin{array}{l}\text { Frequency } \\
(\mathbf{n})\end{array}$ & $\begin{array}{l}\text { Percentage } \\
(\%)\end{array}$ \\
\hline Preoperative antibiotics & & \\
\hline Amixyclavulanate+metronidazole & 111 & 55.5 \\
Ceftriaxone+metronidazole & 82 & 41.0 \\
Others & 7 & 3.5 \\
Total & 200 & 100 \\
\hline Culture yields and microscopy & & \\
\hline Staphylococcus aureus & 19 & 61.3 \\
Klebsiella spp & 5 & 16.1 \\
Pseudomonas aeruginosa & 4 & 12.9 \\
Streptococcus pyogenes & 3 & 9.7 \\
Total & 31 & 100 \\
\hline
\end{tabular}

Table 3. Distribution of wound characteristic of participants.

\begin{tabular}{lll}
\hline & Frequency $(\mathbf{n})$ & Percentage (\%) \\
\hline Wound class & & \\
\hline Clean & 103 & 51.5 \\
Clean/contaminated & 78 & 39.0 \\
Contaminated & 10 & 5.0 \\
Dirty & 9 & 4.5 \\
\hline Site of surgery (wound) & \\
\hline Abdomen & 182 & 91.0 \\
Others & 18 & 9.0 \\
\hline Type of surgery & & \\
\hline Major & 179 & 89.5 \\
Minor & 21 & 10.5 \\
\hline Cadre of surgeons & & \\
\hline Consultant & 53 & 26.5 \\
Senior registrar & 144 & 72.0 \\
Registrar & 3 & 1.5 \\
\hline
\end{tabular}


Only 31 (15.5\%) participants developed SSI (and had cultures and sensitivity done), while others $(169,84.5 \%)$ did not develop SSI.

A higher proportion of respondents $(18,58.1 \%)$, who developed SSI didn't have pre-morbid health problem, while the rest $(13,41.9 \%)$ had coexisting ill-health. The association between SSI and pre-morbid status (Table 4) was statistically significant $(p=0.007)$.

There was no statistically significant relationship ( $p>0.05)$ between the development of SSI and any of the following factors- age, sex, marital status, educational levels, body mass index (BMI), occupation and socioeconomic class of the subjects.

Table 4. Relationship between development of SSI and operation related characteristics.

\begin{tabular}{|c|c|c|c|c|}
\hline & \multicolumn{4}{|c|}{ Development of SSI } \\
\hline & Yes $(\%)$ & No (\%) & $\mathrm{X}^{2}$ & P-value \\
\hline \multicolumn{5}{|l|}{ Types of operation } \\
\hline Major & $31(16.4)$ & $158(83.6)$ & 2.135 & 0.149 \\
\hline Minor & $0(0.0)$ & $11(100.0)$ & -- & -- \\
\hline \multicolumn{5}{|l|}{ Wound class } \\
\hline Clean & $12(11.7)$ & $91(88.3)$ & 11.621 & 0.009 \\
\hline Clean/contaminated & $11(14.1)$ & $67(85.9)$ & -- & -- \\
\hline Contaminated & $4(40.0)$ & $6(60.0)$ & -- & -- \\
\hline Dirty & $4(44.4)$ & $5(55.6)$ & -- & -- \\
\hline \multicolumn{5}{|c|}{ Premorbid status of patient } \\
\hline Yes & $13(20.0)$ & $52(80.0)$ & 20.979 & 0.007 \\
\hline No & $18(13.3)$ & $117(86.7)$ & -- & -- \\
\hline \multicolumn{5}{|l|}{ Cadre of surgeons } \\
\hline Consultant & $9(17.0)$ & $44(83.0)$ & 0.644 & 0.725 \\
\hline Senior registrar & $22(15.3)$ & $122(84.7)$ & -- & -- \\
\hline Registrar & $0(0.0)$ & $3(100.0)$ & -- & -- \\
\hline Total & $31(15.5)$ & $169(84.5)$ & -- & -- \\
\hline
\end{tabular}

\section{Discussion}

The prevalence of SSI in this was between study and found to be $15.5 \%$ with majority 26 of 31 (83.9\%) of them developing supperficial incisional SSI, 4 of 31 (12.9\%) deep incisional SSI and 1 of 31 (3.2\%) organ space SSI.

This prevalence rate appears to be higher than that obtained by Suljagic et al., in Serbia (6.3\%), Askarian et al., in Iran (2.4\%) and Anderson et al., in USA $[4,16,17]$. It is however lower than the SSI rate obtained in some African countries by Fehr et al., in Tanzania (22\%), and Anguzu et al., in Uganda (58.5\%) [8,9]. The prevalence from other parts of Nigeria also showed higher rates of SSI, e.g., $17.3 \%$ in Lagos, and $23.6 \%$ in Zaria $[\mathbf{1 8}, \mathbf{1 9}]$.

The reason for the high rate of surgical site infection in this study may be due to poor application of aseptic techniques such as inadequate sterilization of surgical operative equipment, inadequate environmental hygiene and lack of running tap water which sometimes may not be available in the hospital. Heavy traffic in the theatre comprising of medical students with unwashed personal theatre wears, may all contribute to the increased rate of SSI.

The lower rate of SSI found in this study compared to rates insome low resource countries such as Uganda and Tanzania may be due to the location of the study; being in rural or remote community practice with minimal standards of hygiene may be responsible for the difference. The level of infrastructural development and application of acceptable surgical technique may count.

\section{Antimicrobial prophylaxis}

It had been severally documented that appropriate use of prophylactic antibiotics pre-operatively lowers the risk of developing SSI [20]. The relationship between SSI and antimicrobial prophylaxis was not significant in this study $(p=0.558)$. The finding in this study does not agree with the study by Duque-Estrada et al., Mawalla et al., and Shah et al., where the relationship was statistically significant [21-23].

The reason for the finding in this study may be due to a very high prevalent use of prophylactic antibiotics. Third generation cephalosporins and metronidazole were used in more than $40 \%$ of the patients. Others, obstetrics patients mainly, received Augmentin and metronidazole. The minor surgeries received ciprofloxacin for 5 days.

Parenteral route of administration was commonly used for 3 days in major surgeries after which it was changed to orals to complete 5 days course of prophylactic antibiotics. Although no studies had been done, most surgeons insist on Rocephine and Mesporin and commonly reject unbranded ceftriaxone. There is no uniform drug formulary for antimicrobial prophylaxis. Each surgeon administers antibiotics according to preference or inherent local practice in a center.

The finding in this study showed that most prophylactic antibiotics was commenced after the surgery. Hence, it became obvious that the rationale for prophylactic use of antibiotics was to compensate for inadequacies in surgical techniques, e.g., wound care, infection control and aseptic techniques.

The liberal use of peri-operative antibiotics in this study is of particular concern giving the rising emergence of multidrug resistant organisms.

\section{Wound class and SSI}

The likelihood of developing SSI is higher in wounds that are contaminated or dirty. The association between developing SSI and wound class in this study is statistically significant $p=0.009$. This study shows that $40-44 \%$ of patients with contaminated/dirty surgical wound class had SSI. The figures compared favourably with the finding by Ameh et al., in Zaria [10]. Erikson et al., in Tanzania recorded similar findings [24]. This similarity is not surprising and it is biologically plausible, because the offending organisms are already established and proliferating in the site before incision.

\section{Premorbid status and SSI}

More than half of the patients who developed SSI had some 
Osakwe et al. Family Practice Reports 2014,

http://www.hoajonline.com/journals/pdf/2056-5690-1-2.pdf

doi: $10.7243 / 2056-5690-1-2$

form of premorbid illness or the other. The association between $\mathrm{SSI}$ and premorbid status is statistically significant $\mathrm{p}=0.007$. The patients that had other co-morbid status of sickle cell disease, cancer, anemia, hepatitis, asthma, etc, have the highest rate of SSI.

Diabetes and HIV have severally been documented as a risk factor for surgical site infections $[\mathbf{2 5}, \mathbf{2 6}]$. The reason for this includes depression of the patient's immunity, thus bacteria colonization of surgical site easily transforms into established infection.

\section{Conclusion}

The prevalence of SSI in this study is high (15.5\%) with Staphylococcus aureus as the commonest implicated pathogen in southeastern Nigeria. The wound-related risk factors associated with SSI were wound class, and premorbid health conditions. Based on this study, the authors make the following recommendations:

1. Optimization of pre-morbid health conditions of patients before elective surgical operation is undertaken.

2. There is need for further research on comparative analysis of patients with premorbidity and control.

3. Improving the surgical techniques, e.g., adequate aseptic techniques, infection control and surgical operating skills.

\section{Limitations of the study}

1. Observer bias in identifying SSI. However it is possible that under-reporting and over-reporting on both side will cancel out, leaving the report to be valid.

2. Inability to culture anaerobic organisms could affect the interpretation of type of micro-organism.

\section{Competing interests}

The authors declare that they have no competing interests.

Authors' contributions

\begin{tabular}{|l|c|c|c|c|c|}
\hline Authors' contributions & OJO & GAN & CRO & UA & HNC \\
\hline Research concept and design & $\checkmark$ & $\checkmark$ & $\checkmark$ & $\checkmark$ & $\checkmark$ \\
\hline Collection and/or assembly of data & $\checkmark$ & $\checkmark$ & $\checkmark$ & $\checkmark$ & $\checkmark$ \\
\hline Data analysis and interpretation & $\checkmark$ & $\checkmark$ & -- & -- & -- \\
\hline Writing the article & $\checkmark$ & $\checkmark$ & $\checkmark$ & $\checkmark$ & $\checkmark$ \\
\hline Critical revision of the article & $\checkmark$ & $\checkmark$ & -- & -- & -- \\
\hline Final approval of article & $\checkmark$ & $\checkmark$ & -- & -- & -- \\
\hline Statistical analysis & $\checkmark$ & $\checkmark$ & -- & -- & -- \\
\hline
\end{tabular}

\section{Acknowledgement}

We acknowledge with thanks Dr. Paul Obiegbu and Dr. Berthrand Obi Nwosu for their kind advice and critical input during the initial preparation of the manuscript.

Publication history

Editors: Soornarain Subramoney Naidoo, Durban University of Technology, South Africa.

Waris Qidwai, Aga Khan University, Pakistan.

Received: 01-Ju1-2014 Final Revised: 24-Aug-2014

Accepted: 26-Aug-2014 Published: 18-Sep-2014

\section{References}

1. Okeke IN, Aboderin OA, Byarugaba DK, Ojo KK and Opintan JA. Growing problem of multidrug-resistant enteric pathogens in Africa. Emerg Infect Dis. 2007; 13:1640-6. | Article | PubMed Abstract | PubMed Full Text

2. Dahms RA, Johnson EM, Statz CL, Lee JT, Dunn DL and Beilman GJ. Third-generation cephalosporins and vancomycin as risk factors for postoperative vancomycin-resistant enterococcus infection. Arch Surg. 1998; 133:1343-6. | Article | PubMed

3. Bratzler DW. Strategies for the prevention of Surgical site infections: Review of New Multi-specialty Society Guidelines. University of Oklahoma Health Sciences Center. 2012. I Website

4. Anderson DJ, Sexton DJ, Kanafani ZA, Auten G and Kaye KS. Severe surgical site infection in community hospitals: epidemiology, key procedures, and the changing prevalence of methicillin-resistant Staphylococcus aureus. Infect Control Hosp Epidemiol. 2007; 28:1047-53. | Article | PubMed

5. Watanabe A, Kohnoe S, Shimabukuro R, Yamanaka T, Iso $\mathrm{Y}, \mathrm{Baba} \mathrm{H}$, Higashi H, Orita H, Emi Y, Takahashi I, Korenaga D and Maehara Y. Risk factors associated with surgical site infection in upper and lower gastrointestinal surgery. Surg Today. 2008; 38:404-12. | Article | PubMed

6. Allegranzi B, Bagheri Nejad S, Combescure C, Graafmans W, Attar H, Donaldson $L$ and Pittet $D$. Burden of endemic health-care-associated infection in developing countries: systematic review and meta-analysis. Lancet. 2011; 377:228-41. | Article | PubMed

7. Bagheri Nejad S, Allegranzi B, Syed SB, Ellis B and Pittet D. Health-careassociated infection in Africa: a systematic review. Bull World Health Organ. 2011; 89:757-65. | Article | PubMed Abstract | PubMed Full Text

8. Fehr J, Hatz C, Soka I, Kibatala P, Urassa H, Battegay M, Jeffrey Z, Smith T, Mshinda H, Frei R and Widmer AF. Antimicrobial prophylaxis to prevent surgical site infections in a rural sub-Saharan hospital. Clin Microbiol Infect. 2006; 12:1224-7. I Article | PubMed

9. Anguzu JR and Olila D. Drug sensitivity patterns of bacterial isolates from septic post-operative wounds in a regional referral hospital in Uganda. Afr Health Sci. 2007; 7:148-54. | Article | PubMed Abstract | PubMed Full Text

10. Ameh EA, Mshelbwala PM, Nasir AA, Lukong CS, Jabo BA, Anumah MA and Nmadu PT. Surgical site infection in children: prospective analysis of the burden and risk factors in a sub-Saharan African setting. Surg Infect (Larchmt). 2009; 10:105-9. | Article | PubMed

11. Osifo OD and Aghahowa SE. Audit of antibiotic therapy in surgical neonates in a tertiary hospital in Benin City, Nigeria. Afr J Paediatr Surg. 2011; 8:23-8. | Article | PubMed

12. Ojiyi EC, Dike El, Okeudo C, Ejikem EC and Nzewuihe ACE. Wound infection following Caesarean Section in a University Teaching Hospital in South-East Nigeria. Orient J Med. 2013; 25:1-2. I Pdf

13. Israel GD. Determining sample size. IFAS Extension, University of Florida. PEOD-6. 2013. | Pdf

14. WHO. A guide to rapid assessment of human resources for health. WHO Geneva. 2004. | Pdf

15. Nnajieto CC. An Introduction to sociology of eduction. Divine Mercy Publishers, Owerri. 2006; 54-93.

16. Suljagic V, Jevtic $M$, Djordjevic $B$ and Jovelic A. Surgical site infections in a tertiary health care center: prospective cohort study. Surg Today. 2010; 40:763-71. | Article | PubMed

17. Askarian $\mathrm{M}$, Yadollahi $\mathrm{M}$ and Assadian O. Point prevalence and risk factors of hospital acquired infections in a cluster of university-affiliated hospitals in Shiraz, Iran. J Infect Public Health. 2012; 5:169-76. | Article I PubMed

18. Mofikoya BO, Neimogha MI, Ogunsola FT and Atoyebi OA. Bacterial Agents of Abdominal Surgical Site Infections in Lagos, Nigeria. European Journal of Scientific Research. 2009; 38:509-513.

19. Adegoke AA, Tom M, Okoh Al and Jacob S. Studies on multiple antibiotic resistant bacteria isolated from surgical site infection. Sci Res Essays. 2010; 5:3876-3881. | Pdf 
Osakwe et al. Family Practice Reports 2014,

http://www.hoajonline.com/journals/pdf/2056-5690-1-2.pdf

20. Bratzler DW and Houck PM. Antimicrobial prophylaxis for surgery: an advisory statement from the National Surgical Infection Prevention Project. Clin Infect Dis. 2004; 38:1706-15. | Article I PubMed

21. Mawalla B, Mshana SE, Chalya PL, Imirzalioglu C and Mahalu W. Predictors of surgical site infections among patients undergoing major surgery at Bugando Medical Centre in Northwestern Tanzania. BMC Surg. 2011; 11:21. | Article | PubMed Abstract | PubMed Full Text

22. Duque-Estrada EO, Duarte MR, Rodrigues DM and Raphael MD. Wound infections in pediatric surgery: a study of $\mathbf{5 7 5}$ patients in a university hospital. Pediatr Surg Int. 2003; 19:436-8. I Article I PubMed

23. Shah FH, Gandhi MD, Mehta VP, Udani DL and Mundra MP. Swadia: Nosocomial Infections in Surgical Wards. The Internet Journal of Surgery. 2010; 24:1. | Article

24. Eriksen HM, Chugulu S, Kondo S and Lingaas E. Surgical-site infections at Kilimanjaro Christian Medical Center. J Hosp Infect. 2003; 55:14-20. I Article | PubMed

25. Xing D, Ma JX, Ma XL, Song DH, Wang J, Chen Y, Yang Y, Zhu SW, Ma BY and Feng R. A methodological, systematic review of evidence-based independent risk factors for surgical site infections after spinal surgery. Eur Spine J. 2013; 22:605-15. | Article I PubMed Abstract | PubMed Full $\underline{\text { Text }}$

26. Zhang L, Liu BC, Zhang XY, Li L, Xia XJ and Guo RZ. Prevention and treatment of surgical site infection in HIV-infected patients. BMC Infect Dis. 2012; 12:115. | Article | PubMed Abstract | PubMed Full Text

\section{Citation:}

Osakwe JO, Nnaji GA, Osakwe RC, Agu U and Chineke $\mathrm{HN}$. Role of premorbid status and wound related factors in surgical site infection in a tertiary hospital in sub-saharan Africa. Fam Pract Rep. 2014; 1:2. http://dx.doi.org/10.7243/2056-5690-1-2 